\title{
NOVA GESTÃO PÚBLICA E EDUCAÇÃO: A TRAJETÓRIA DA POLÍTICA DO QUEBEC DE “GESTÃO ORIENTADA POR RESULTADOS”
}

\author{
Christian Maroy* \\ Cécile Mathou* \\ SAMUEl VaillancourT ${ }^{*}$ \\ AnNelise VoIsIn ${ }^{*}$
}

\begin{abstract}
RESUMO: Este artigo centra-se na trajetória (BALL, 1997) da política educacional de "gestão orientada por resultados" ("gestion axée sur les résultats" - GAR) no Quebec desde 2000 mobilizando a sociologia da ação pública. (MULLER, 2000) Para tal, vários "relatos de ação pública" (RADAELLI, 2000) usados pelos criadores, pelas partes interessadas e beneficiários dessa política são revelados. Os resultados da análise evidenciam a sedimentação e a hibridização de medidas reportando-se à prestação de contas comunitária ou performativa. $\mathrm{O}$ texto mostra um processo de recontextualização "neo-estatista" da nova gestão pública em pratica na trajetória da política de educação do Quebec, a qual reforça o papel do Estado na gestão da educação.
\end{abstract}

Palavras-chave: Política educacional; Gestão orientada por resultados; trajetória da ação pública; Relatos de ação pública; Nova gestáo pública; Quebec (Canadá).

\section{NEW PUBLIC MANAGEMENT AND EDUCATION: THE QUEBEC POLICY TRAJECTORY OF "GESTION AXÉE SUR LES RÉSULTATS"}

ABSTRACT: This article presents the trajectory (BALL, 1997) of the
Quebec education policy called "Gestion axée sur les résultats" (GAR)
or "results-based management" implemented since 2000, drawing on
the sociology of public action (MULLER, 2000). In order to do this, we
study the various "policy narratives" (RADAELL, 2000) put forward
by the policy makers and the stakeholders involved in and affected
by the policy. The results of the analysis highlight the layering and
hybridization of measures pertaining to different logics, "community-

* University of Montreal, Canada Research Chair in Educational Policies. Canadá, Montreal. E-mail de contato: christian.maroy@umontreal.ca. 
based accountability" and "performative" accountability. The paper argues that there is "neo-statist" recontextualisation of the new public management in the Quebec education policy, which reinforces the place of the State in the management of the education system.

Keywords: Education policy; Result-based management; Policy trajectory; Policy narratives; New public management; Quebec (Canada).

\section{NOUVELLE GESTION PUBLIQUE ET ÉDUCATION: LA TRAJECTOIRE DE LA POLITIQUE QUÉBÉCOISE DE “GESTION AXÉE SUR LES RÉSULTATS"}

RÉSUMÉ: Cet article porte sur la trajectoire (BALL, 1997) de la politique éducative de "gestion axée sur les résultats" (GAR) au Québec depuis 2000 en mobilisant la sociologie de l'action publique. (MULLER, 2000) Pour ce faire, plusieurs "récits d'action publique" (RADAELLI, 2000) portés par les promoteurs, parties prenantes et destinataires de cette politique sont mis au jour. Les résultats de l'analyse mettent en évidence la sédimentation et l'hybridation de mesures qui relèvent soit d'une accountability "communautaire" soit d'une accountability "performative". Le texte montre un processus de recontextualisation "néo-statiste" de la nouvelle gestion publique à l'œuvre dans la trajectoire de la politique éducative québécoise, qui renforce la place de l'État dans la gestion de l'éducation.

Mots-clés: Politique éducative; Gestion axée sur les résultats; trajectoire de l'action publique; Récits d'action publique; Nouvelle gestion publique; Québec (Canada).

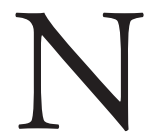

osso objetivo ${ }^{1}$ é analisar a trajetória daquela convencionalmente chamada de Gestion axée sur les résultats - GAR (Gestão orientada por resultados) no sistema educacional do Quebec. A GAR é uma política que visa influenciar substancialmente os modos de regulação institucionais no sistema educacional, que foi atualizada no âmbito legislativo na década de 2000 por três leis (Lei 82, 124 e 88). Essa política estabelece novas ferramentas (planejamento, contratação, prestação de contas) para melhor alinhar os objetivos e o funcionamento das escolas com os objetivos fixados nos âmbitos de ação "superiores": o nível intermediário constituído pelas Comissões Escolares (CE) e o nível provincial ${ }^{2}$, ou seja, o Ministério da Educação, Lazer e Esporte (MELS). Este alinhamento converge, portanto, aos "resultados" direcionados a diferentes níveis de ação do sistema. Vemos nesta primeira análise que se trata de uma versão quebequense de uma obrigação de resultados (LESSARD; MEIRIEU, 2004) onde novos modos de regulação se sobrepõem às regulamentações existentes de natureza burocrática ou profissional. (MAROY, 2008) ${ }^{3}$ 
Não se pode dissociar a Gestão orientada por resultados (GAR) da institucionalização de alguns princípios referentes à Nova Gestão Pública (NGP). ${ }^{4}$ (HOOD, 1991) No entanto, a NGP desenvolveu-se pela "sedimentação" (BÉZES, 2005), integrando-se de maneira mais ou menos fragmentada às lógicas de ação das administrações públicas dos países ocidentais ao longo dos anos de 1980 e de 1990. Isso ilustra, em primeiro lugar, que os modelos multinacionais da NGP não são monolíticos (HOOD, 1995) e, por outro lado, que vários processos institucionais de sedimentação, hibridação ou dependência de caminho podem atuar na construção dessas reformas gerenciais.

No Quebec, defendemos a tese de uma mistura dos princípios da NGP com a postura de uma forte valorização do Estado e de um modelo de regulação burocrática que persiste em ser influente. Além disso, no campo educacional, defendemos que os princípios neogerenciais se imbricam a um modo de regulação comunitária, favorecendo as necessidades e preocupaçóes das comunidades locais ou de usuários individuais. (BARROSO, 2000; MAROY; DUPRIEZ, 2000) A GAR certamente deriva da NGP, mas baseia-se nas instituiçóes existentes e que são defendidas por alguns no debate público. O interesse da "gestão orientada por resultados" é, portanto, mais próximo de uma versão neoestatista da Nova Gestão Pública, que de uma variante "neoliberal". (CLARK, 2002) Uma NGP neoestatista vista de maneira inovadora pelas administrações públicas, deixa um lugar relativamente importante ao Estado, que permanece valorizado e cuja legitimidade não é questionada. Quanto à NGP "neoliberal”, essa sim provoca diminuição do papel do Estado, de suas estruturas e campos de ação, em prol do setor privado e da concorrência.

A trajetória de uma política educacional não deve ser concebida em uma perspectiva linear e cronológica. Da mesma forma que Ball (1994), consideramos uma política como um movimento de construção de um conjunto de discursos, instrumentos, instituiçóes e relaçóes sociais cuja disposição e configuração são transformadas ao longo do tempo, envolvendo vários processos de mudanças das instituições existentes, mas também de invençóes de novas categorias. Nosso objetivo é desvendar alguns dos pontos em torno dos quais foi construída a GAR nas últimas duas décadas. Mostraremos que a GAR se constrói incorporando, sedimentando e justapondo discursos e instrumentos de açáo pública derivados de acontecimentos políticos anteriores, que levaram, em primeiro lugar, à evolução dos objetivos de igualdade das políticas educacionais "do acesso ao sucesso"; em segundo lugar, ao desenvolvimento de uma política chamada de descentralização. $\mathrm{O}$ discurso específico à GAR desenvolve-se nesta via dupla e tende a redefinir o seu significado.

Em uma primeira parte, propomos uma releitura da literatura existente sobre as políticas educacionais no Quebec, nos últimos anos, para apresentar os principais elementos que parecem ser mobilizados, ativados e, às vezes, trans- 
formados na definição da política da GAR durante a década de 2000. Assim, apresentaremos alguns dos instrumentos de ação pública, categorias cognitivas, valores ou argumentos normativos, e instituiçóes formais que serão mobilizados ou incorporados mais tarde nos discursos que contribuem para a construção real da GAR. Consideramos tais instrumentos como instituiçôes em sentido amplo (concomitantemente regras, normas e ideias; SCOTT, 1995) que definem ou afetam a trajetória dessa política.

Em uma segunda parte, vamos nos concentrar no período recente desta política de construção (2000-2010), analisando relatos de ação pública 5 (RADAELLI, 2000), através dos quais diferentes atores tendem a dar um significado, ou alterar, a definição da Gestão orientada por resultados (GAR) no Quebec. Demos maior ênfase ao componente cognitivo das políticas públicas (MULLER, 2000). Tendo como inspiração Fouilleux (2000), consideramos o cenário político central - a Assembleia Nacional do Quebec (AN) e a Comissão de Cultura e Educação da Assembleia Nacional (CCEAN) - como componente do "Fórum da Comunidade da Produção de Políticas Educacionais" (FCPE), no Quebec . Esse fórum contribui na construção da política por meio de consultas, debates parlamentares ou interaçóes dos participantes. É exatamente nesse fórum que se manifestam e ocorrem os relatos de ação pública. Analisamos, assim, os materiais discursivos provenientes deste fórum ${ }^{7}$, tomando as categorias conceituais de análise de relatos públicos como base de nossa abordagem de codificação analítica para apresentar as semelhanças e diferenças na construção das "histórias casuais" feitas pelos atores envolvidos.

Discutiremos na terceira parte, algumas mediações através das quais a NGP é construída, de acordo com um caminho específico - neoestatista - no contexto do Quebec. Pela mobilização de uma perspectiva neoinstitucionalista, que destaca os processos em andamento na construção da trajetória da GAR, no sistema do Quebec, vamos defender a tese de que existe uma mistura dos princípios da NGP com a postura de uma forte valorização do Estado e de um modelo de regulação burocrática que começa a ser influente.

\section{Trajetória da política educacional no Quebec e a construção da Gestão orientada por resultados}

No Quebec, a educação foi, por muito tempo, organizada sobre bases confessionais (católicas ou protestantes). Tal fato refletiu-se nas estruturas do sistema de ensino. A estrutura central foi controlada, na prática, pelo Comitê Católico e pelo Comitê Protestante, que atuaram, na realidade, como dois sistemas escolares paralelos. No nível intermediário, as Comissóes Escolares (forma de governo escolar local, liderada por representantes eleitos e com poder de tributação) estavam 
relacionadas com hierarquias religiosas. E finalmente, a educação foi ancorada e colocada no centro das atenções do Estado graças ao período conhecido como a "Revolução Tranquila" e da influente Commission royale d'enquête sur l'enseignement dans la province de Québec (conhecida como Commission Parent, nome de seu presidente, 1963). Além de estruturas formais chaves do sistema de ensino atual (Ministério da Educação, estabelecimentos escolares públicos primários e secundários, currículo e planos pedagógicos relativamente unificados), essa Comissão promoveu duas ideias principais que constituem as convençóes sociais (portanto, instituiçóes no sentido normativo) amplamente compartilhadas, mesmo que elas não sejam incontestadas: a educação para todos e a definição de um projeto educacional "nacional", de um projeto político de desenvolvimento e modernização da sociedade do Quebec, através da educação. (CORBO, 2002) As organizaçóes, atores e regulamentos, que apareceram nos últimos 50 anos, vão colaborar para orientar a recontextualização e a recepção de princípios neogerenciais dos anos 1980/1990, não no sentido de uma promoção sistemática de "mercado" e "menos Estado", mas no sentido de uma política mais focada na transformação dos meios utilizados, pelo Estado central, em educação, em busca por uma maior eficiência e eficácia do projeto coletivo.

Entretanto, faz-se necessário destacar que a Commission Parent propunha também a transformação da instância intermediária e da democracia escolar representadas pelas comissóes escolares. Essas seriam entidades territoriais únicas encarregadas " $\mathrm{da}$ responsabilidade administrativa e financeira das escolas do território" e ainda supervisionadas por uma instância de coordenação supraterritorial. Paralelamente, visava-se dar aos pais um papel de liderança em uma gestão local participativa através dos "comitês escolares", onde os pais seriam os únicos eleitores. (ROCHER, 2004, p. 11) Essa recomendação não foi implementada, porém o ideal de democracia e de gestão participativa influenciará o debate sobre a autonomia dos estabelecimentos escolares e também sobre a "descentralização" ocorrida nos anos 1970/1980, em consequência das críticas à excessiva centralização ministerial, mas também sob a influência de modelos internacionais que promovem "a autonomia do estabelecimento escolar". (BRASSARD, 2007) Assim, a noção de "projeto educacional" do estabelecimento escolar aparece (em 1977) e, com ele, a (re)valorização do controle local da educação. Dez anos depois, a ideia de uma gestão local (de âmbito limitado) pelo "projeto educacional" e os "conselhos escolares" é traduzida em várias leis sucessivas. Acima de tudo, visando à integração do estabelecimento escolar na comunidade, em nome de princípios associados a uma gestão comunitária e participativa. (LESSARD et al., 2007, p. 7)

Ao mesmo tempo uma segunda questão emerge, aquela que aborda o "sucesso". Desde o final dos anos de 1980, as vozes nos meios educacionais ou acadêmicos buscam colocar em pauta o problema do fracasso e do abandono escolar, sobretudo entre os meninos. (PROULX, 2007) Deniger (2012, p. 71) aponta 
o importante papel da Central de Ensino do Quebec (sindicato dos professores) e sua "[...] forte campanha pelo sucesso escolar [ver CEQ 1991] [que] obrigou o Estado e a sociedade civil a agirem perante uma situação tida como um grave problema social [...]". Assim, em 1992, no plano de ação "À chacun ses devoirs", o Ministério da Educação de Quebec (MEQ) estabelece uma meta de "80\% de conclusão do secundário no prazo de cinco anos" (MEQ, 1992). Este problema também será dominante durante os États généraux sur l'éducation (ÉGÉ, 1996) que constituem um momento-chave no debate escolar quebequense, momento exigido, sobretudo, pelas organizaçôes sindicais, acadêmicas e alguns meios da imprensa. Essa nova problemática demonstra uma evolução no conceito de igualdade de oportunidades, discutidos desde o relatório Parent em termos de acessibilidade escolar: igualdade na educação não se refere apenas à igualdade de oportunidades de "acesso" (favorecida pela gratuidade e divisão igualitária da oferta educativa), mas à igualdade de oportunidades de "sucesso". Na reforma proveniente dos États généraux sur l'éducation, isso se traduz no objetivo de "sucesso para todos".

Os ÉGÉ também prolongam a dinâmica da descentralização. Com o projeto de lei $180^{8}$ o objetivo torna-se claro: "[...] reforçar o papel dos atores locais e o envolvimento da comunidade na governança educacional [...]”. (DEMBÉLÉ et al., 2013, p. 59) Assim, encontramos uma nova distribuição de poder em favor dos estabelecimentos escolares, aos quais é concedida uma maior autonomia. Isso resulta, principalmente, na devolução de funçóes e de poderes das CE aos estabelecimentos e por um relaxamento da organização do trabalho, em termos de gestão dos recursos e processos educacionais na promoção da adaptabilidade dos serviços da escola ao público envolvido. (MAROY et al., 2013) Além disso, os pais saem mais fortalecidos como atores do ambiente escolar, sobretudo no que diz respeito à necessidade de criar um conselho de estabelecimento, onde teriam paridade em número com os funcionários da escola. (LESSARD et al., 2007)

Desde então, a preocupação por "resultados” está presente (BRASSARD, 2007). No entanto, somente a partir de 2000 , constata-se que a meta por uma melhora dos índices de sucesso do sistema será explicitamente associada a um desejo de construir mais "coerência global" no sistema educacional e mais prestação de contas dos níveis de base aos níveis superiores. O movimento de descentralização é então compensado por uma reforma geral da administração pública.

Em princípio, o projeto de lei $82^{9}$ estabelece uma política de gestão orientada por resultados em toda a administração pública ${ }^{10}$. Assim, no MELS, a GAR é refletida na aplicação de planejamento estratégico e desenvolvimento de instrumentos permitindo o acompanhamento estatístico do desempenho do sistema de ensino. Em 2002, o Partido Quebequense (PQ) apresentou o projeto de lei $124^{11}$, que estende a lógica da GAR para o sistema escolar público: determinando como obrigatório o planejamento estratégico nas CE e impóe aos 
estabelecimentos escolares uma definição de planos de desempenho, os quais precisam "operacionalizar" os seus projetos educacionais.

O projeto de lei $88^{12}$ aprovado seis anos mais tarde, sob o governo do Partido Liberal do Quebec (PLQ), vai ainda mais longe, ao exigir que a prestação de contas dos níveis inferiores aos níveis superiores se faça baseada em resultados obtidos em relação aos "objetivos mensuráveis" previamente definidos. Adiciona ainda uma forma de contratualização: "acordos de parceria" (AP) entre o Ministério e a CE, são os "Contratos de Gestão e Desempenho Escolar" (CGDE) entre CE e estabelecimentos de ensino. Destaca-se o compromisso de cada nível em contribuir para a realização do conjunto de metas e objetivos mensuráveis definidos no nível superior, propondo desenvolver um senso de alinhamento dos níveis de ensino. Em seguida, em efeito cascata, as $\mathrm{CE}$ e os estabelecimentos devem especificar em que medida os seus próprios planos "contribuem" para a realização dos objetivos do Ministério em relação ao desempenho. Trata-se de um mecanismo de "recentralização" potencialmente poderoso. A flexibilidade do nível local é extremamente reduzida, apesar da paradoxal autonomia de gestão.

Entretanto, esses novos mecanismos de coordenação "verticais" "sedimentam-se" nos arranjos institucionais feitos a partir dos ÉGÉ. Para Lessard et al. (2007), as transformaçóes associadas à GAR estão em tensão com aquelas resultantes dos ÉGÉ; as regulaçóes locais (comunitárias ou comerciais) devem se fundir hibridamente com as novas regulaçóes impostas pelo nível superior (currículo padronizado e obrigação por resultados). A marcante presença de uma burocracia educacional hierárquica, principalmente no âmbito das CE, é reforçada (BRASSARD, 2009), sobrepondo-se assim aos elementos de uma governança local. Todavia, o controle exercido pelo Estado transformou-se: volta-se ao desempenho por mecanismos de prestação de contas, reforçado pelo conjunto de metas ministeriais e ferramentas de medição - indicadores de desempenho - que estruturam não apenas a ação possível, mas também a concepção de ação pública.

\section{A Gestão orientada por resultados e os relatos de ação pública}

Nesta seção, explicaremos os relatos de ação pública a partir de uma análise de conteúdo dos debates e "memórias" apresentados pelos vários atores sociopolíticos durante as sessôes da Comissão de Cultura e Educação da Assembleia Nacional, dedicados a dois projetos de lei abordando a GAR no campo educacional.

Os relatos de ação pública são estruturados em torno de um conjunto de elementos mobilizados pelos atores: a formulação dos desafios do sistema educacional e dos problemas por ele enfrentados; a proposta de um repertório de 
ações/soluções para esses problemas; a ênfase na identificação das consequências previsíveis da implementação efetiva dessas soluçóes e/ou da não-ação. A análise dos relatos procura identificar os termos sobre os quais se constrói o debate que envolve a GAR no Quebec. Esses incorporam e combinam muitas ideias, categorias, relaçóes causais (realizadas em outros fóruns), ferramentas, instituiçóes ou princípios da justificação (novos ou antigos) que são, assim, defendidos, adquiridos, denunciados ou revalorizados, de acordo com o curso da ação política que os relatos de ação pública tendem a promover. Este trabalho discursivo e estas controvérsias não podem, contudo, ser separados das relações de força e de interesses entre os diferentes atores envolvidos. (MULLER, 2000)

Nossa análise converge claramente para três complexos relatos. O primeiro relato feito pelos atores encarregados das responsabilidades de "governança escolar" - os partidos políticos (PQ e PLQ) alternadamente no poder, ou na oposição, durante o período de abrangência do relatório e também de onde vieram os ministros encarregados do Ministério da Educação; os atores das $\mathrm{CE}^{13}$ representantes dos pais, estes produziram o relato dos "governantes", chamado assim, visto que os atores em sua maioria são responsáveis por um ou outro nível de responsabilidade escolar. Em segundo lugar, um relato "alternativo" feito por um partido de oposição - Ação democrática do Quebec (ADQ) -, que nunca governou, e uma federação de diretores de escolas. O terceiro relato, chamado de "sindical", pois fornecido pelos sindicatos de professores (CSQ, FAE e CSN) ${ }^{14}$. Esses relatos permanecem relativamente estáveis entre os dois momentos legislativos analisados.

O relato dos "governantes" destaca dois principais tipos de problemas enfrentados pelo sistema escolar do Quebec: por um lado, o abandono e o fracasso escolar que são apenas o lado inverso da necessidade de promover o "sucesso de todos" ou, pelo menos, de um "maior número"; de outro lado, a democracia escolar que funciona mal e deve ser dinamizada e revalorizada. Essas questôes são, de fato, amplamente partilhadas pelos outros dois relatos, mas as soluçóes para o problema divergem fortemente. O relato dos "governantes" vincula esses problemas à falta de eficiência e legitimidade das estruturas do sistema de ensino; evidencia a falta de coordenação e coerência da ação dos diferentes níveis do sistema, bem como a falta de envolvimento da população nas eleiçóes escolares. O resultado é uma "teoria da ação pública" que se baseia na melhoria da eficácia organizacional e da transparência das estruturas existentes. As soluçôes, portanto, passam pela manutenção dos três níveis do sistema (Ministério, CE, estabelecimentos escolares), mas também por uma melhoria do alinhamento e da coordenação de suas ações. Além disso, este relato demostra a necessidade de uma maior prestação de contas das instâncias locais às instâncias superiores e à população com relação aos resultados atingidos. Assim, a eficiência do sistema no desempenho será reforçada por instrumentos de planejamento estratégico, de contratualização (as CP - Conventions 
de Partenariat - e as CGRÉ - Conventions de Gestion et de Réussite Éducative) e de prestaçáo de contas (relatórios dos resultados mensuráveis para os pais ou para o público, para a CE ou para o Ministério). Ao mesmo tempo, a legitimidade democrática da ação dessas estruturas perante os cidadãos, que as financiam, será garantida através de mecanismos de transparência e de prestação de contas dos resultados, tanto à populaçáo local e usuários diretos dos serviços escolares, como às autoridades políticas. Todos esses recursos devem contribuir para uma maior eficácia e eficiência da ação da rede pública, um melhor serviço aos usuários, reforçando sua legitimidade democrática junto à população quebequense.

O relato "alternativo" compartilha os desafios de sucesso e de democracia escolar do primeiro relato, mas é mais alarmista, argumentando que a perda de confiança dos usuários envolve uma crise de confiança na escola pública causada, principalmente, pela deficiência do nível intermediário do sistema de ensino, ou seja, a CE. A "teoria da ação pública" resultante do processo exige um questionamento dessas estruturas. Precisa-se fortalecer a autonomia institucional e eliminar ou reduzir, pelo menos de forma significativa, a função do nível intermediário. É necessário dar maior flexibilidade às escolas, fortalecer a descentralização de recursos e poderes de gestão, e assegurar o exercício da democracia escolar para as escolas. $\mathrm{O}$ fato de os estabelecimentos terem para si as responsabilidades escolares e a sua prestação de contas aos usuários locais e ao Ministério de seus resultados permitirá, simultaneamente, valorizar o desempenho e a resposta às necessidades dos usuários. Cidadãos que poderão, de fato, se expressar tanto pela democracia escolar local como também pelas escolhas de escolas.

Quanto ao relato sindical, ele retoma os problemas comuns descritos acima - abandono escolar e legitimidade democrática - mas acentua as consequências para toda a sociedade quebequense. Não abordar o problema do abandono escolar levaria a uma maior exclusão social; não abordar questóes de governança e democracia na educação resultaria em uma ameaça para a própria instituição democrática. Além disso, o relato sindical insiste em uma terceira problemática, o retrocesso de um ideal de educação como "bem público" assumido pelo Estado. $\mathrm{Na}$ ausência de mobilização coletiva em direção a esse ideal, é todo o sistema de ensino que correria o risco de naufragar em uma lógica de competição reforçada pelas desigualdades sociais e sujeitando a educaçáo à "interesses de mercado". O relato sindical defende uma ação pública visando à igualdade de oportunidades baseada em um projeto de educação básica, acessível a todos, cujo objetivo seria um acentuado sucesso do desempenho escolar e tendo como finalidade primordial o desenvolvimento da sociedade do Quebec. Trata-se, portanto, de priorizar as necessidades dos alunos. Eles devem ter acesso à mesma qualidade de serviços educacionais e às mesmas condiçóes para o seu desempenho escolar. Neste contexto, a ação pública deve garantir a mobilização de funcionários da escola e a autonomia de sua ação pedagógica. O suporte a este pessoal é condição sine qua 
non para o sucesso de sua maioria, já que a qualidade dos serviços educacionais oferecidos depende disso. Três mecanismos seriam as chaves para o sucesso desta ação pública renovada. O primeiro é um papel proativo do Estado e seus componentes para garantir a disponibilidade e o acesso à educação (bem público), como também definir as diretrizes gerais. O segundo mecanismo proposto implica em manter a coesão de um sistema de ensino público e de garantir a universalidade do acesso, o que exige a manutenção dos níveis já existentes (Ministério, Comissão Escolar, estabelecimentos) e reforçar seu alinhamento em torno do ideal de educação do qual o Estado se faz responsável. O terceiro é a vitalidade da democracia nas escolas, juntamente com mecanismos de governança que envolvam os vários atores interessados, sobretudo os funcionários, quando tomam decisões. Nesta perspectiva democrática é que definimos a prestação de contas: ela visa tornar o funcionamento de organizaçóes escolares transparente. Não deveria ser uma "obrigação de resultados", em função de metas quantificadas.

Uma linha de oposição evidente aos outros relatos é criada em relação a certas soluçôes baseadas em princípios neogerenciais, assim que são aplicados no nível dos estabelecimentos. Primeiramente, oposição ao fato de se medir o desempenho e à avaliação de resultados quantificáveis (ponto chave no relato dos governantes) deve ser entendida como um desafio ao sucesso escolar desenvolvido no relato sindical. O sucesso é visto como um fenômeno complexo e seus determinantes, multifatoriais, não apenas escolares. Portanto, não podemos julgar a escola e seu pessoal como os únicos responsáveis pelos resultados dos alunos. O sucesso "do maior número possível" deve ser considerado como um "ideal a cumprir” coletivamente, mas não é realizado sem dificuldades. Além disso, estes mecanismos podem gerar uma desmobilização dos funcionários da escola, crucial para o sucesso do aluno. Finalmente, há oposição às soluçóes enfatizadas no relato "alternativo": autonomia do funcionamento dos estabelecimentos em resposta às necessidades dos usuários/contribuintes. $\mathrm{Na}$ verdade, o relato sindical apoia claramente a ideia de consolidação do caráter público da educação: o Estado deve assumir o papel de "líder nacional" e as CE constituem níveis necessários ao sistema de ensino. A supervisão das escolas pelas CE é legítima, entretanto essas últimas devem ser melhor supervisionadas pelo Estado e contribuir para o caráter público da educação.

\section{Os mecanismos institucionais de uma trajetória neoestatista da Gestão orientada por resultados}

Defendemos a tese de que a trajetória da política de Gestão orientada por resultados no Quebec cresceu ao longo de um caminho que pode ser qualificado de Nova Gestáo Política neoestatista (néo-étatiste). Encontramos uma mistura 
de princípios da NGP com uma forte valorização do Estado e de um modelo de regulação burocrática que continua influente. Esta versão neoestatista foi colocada sob uma nova perspectiva pelas administraçóes (centrais, intermediárias e locais) que devem se preocupar com as necessidades dos usuários e serem mais eficientes. Por outro lado, a versão "neoliberal” da NGP (CLARK, 2002) evidencia a redução dos gastos públicos e dos déficits, assim como a promoção dos serviços públicos baseados na substituição do mercado pelos serviços propostos pelos organismos públicos.

Um duplo raciocínio pode ser evocado para sustentar essa interpretação. De um lado, um argumento de natureza neoinstitucionalista ressalta vários processos que permitem inserir o que já existe, transformando-o. De outro lado, a trajetória realizada nos anos 2000 beneficiou-se de uma convergência parcial dos "relatos de ação pública" dos governantes e das organizaçóes sindicais, em detrimento da visão mais neoliberal do relato alternativo.

\section{Empilhamento e sedimentação dos dispositivos de gestão da educação}

Quanto ao argumento neoinstitucionalista, podemos retomar a interpretação de Bézes (2005) na qual a NGP desenvolve-se por "sedimentação", integrando-se de maneira mais ou menos parcial às lógicas de ação das administrações públicas, sem alterá-las profundamente. Como discutido anteriormente, pode-se constatar que existe, acima de tudo, ao longo da trajetória desta política, construção e implementação de ferramentas e dispositivos institucionais que se empilham. Primeiramente, os "planos estratégicos" ou "planos de sucesso" implantados são articulados com os objetivos locais e nacionais, enquanto antecipam ferramentas que organizam a "participação" e a prestação de contas dos estabelecimentos escolares ou das Comissóes Escolares (CE) à comunidade local ou aos pais. Em seguida, essas duas primeiras geraçôes de ferramentas associam-se às "convençôes" (CP e CGRÉ) que organizam mais formalmente a prestação de contas e alinham os diferentes níveis do sistema, exigindo dos níveis inferiores (CE ou estabelecimentos) a definição de objetivos a seguir, mas também a sua justificativa a partir de dados quantificados. Baseando-se na política da GAR, o empilhamento e a sedimentação desses dispositivos demonstram uma preocupação em associar a "busca da eficácia" de escolas públicas e a "busca de legitimidade da escola junto aos usuários”, o que marca a orientação neoestatista da NGP.

No entanto, o empilhamento de instrumentos de ação política não é garantia de uma lógica de ação, nem coerente e nem única, no funcionamento real das CE e dos estabelecimentos. Nossos trabalhos sobre a implantação da GAR, em quatro Comissões Escolares, mostram, de fato, que a última geração de ferra- 
mentas contratuais primam por ferramentas de prestação de contas à comunidade e isso por várias razões. Em primeiro lugar, as ferramentas de prestação de contas vertical podem resultar em consequências formais ${ }^{15}$. Além do mais, o conjunto de dispositivo contratual vertical tem sido alvo de um significativo investimento organizacional nas CE estudadas (desenvolvimento de ferramentas, prestação de contas vertical diretamente controlada pela administração geral etc.). Assim, esse dispositivo baseia-se nas ferramentas de regulação pelo conhecimento (PONS; VAN ZANTEN, 2007) que acentuam a "responsabilização" dos atores através de consequências simbólicas a eles associadas (relacionadas à comparação de escolas, de classes ou mesmo de alunos, com base em seus resultados).

$\mathrm{Na}$ realidade, o empilhamento de dispositivos leva, portanto, a uma forma de atrofia de certos arranjos institucionais que não são modificados ou atualizados em relação às mudanças de contextos reais nos quais estão implantados; trata-se de um tipo de mudança institucional, qualificada como "a deriva" (drift) por Streeck e Thelen (2005). Os dispositivos mais antigos (de participação local no projeto educacional) perdem, gradualmente, a importância e sua noção de realidade dos estabelecimentos escolares, em favor de dispositivos contratuais e de dispositivos de monitoração (monitoring) baseados em indicadores quantitativos, que são muito mais estruturadores para as $\mathrm{CE}$ e seus estabelecimentos.

\section{Um caminho que passa pelo nível intermediário}

O conceito de dependência de caminho (CAMPBELL, 2004) pode também ser considerado para compreender a direção tomada, no Quebec, pela NGP e pela GAR em direção a essa lógica considerada mais neoestatista. A manutenção do nível intermediário - as CE - pode ser entendida claramente com o presente mecanismo. Em razão dos processos de fusão e desconfessionalização, ocorridos em 1998, as CE, certamente, transformaram-se ao longo das últimas décadas, embora permaneçam como órgãos reguladores intermediários importantes, cujo poder, perante as escolas, tenha sido reforçado na última década. (BRASSARD, 2007) Uma interpretação deste estado de coisas poderia ser a dependência de caminho das políticas em relação a essa estrutura e o que ela representa simbolicamente.

Os sucessivos governos durante a década de 2000 (PQ e PLQ) preferiram propor um modelo de "alinhamento" e de reorganizar coerentemente os níveis intermediários, ao invés de excluí-los (ver o relato dos governantes). A vantagem desta opção para um governo é evitar os obstáculos que se interpóem assim que o Estado tenta suprimi-los ou substitui-los. Esses obstáculos são concomitantemente de ordem econômica, jurídica e socionormativa. Assim, "desmantelar" essas Comissóes Escolares envolve um custo econômico: as CE que se encarregam de alguns serviços (como por exemplo, a gestão de mão de obra e de construçôes) que nem sempre são transferidos para o nível do estabelecimento. Essa situação requer, 
portanto, a criação de um novo órgão com novas missóes, estatutos e métodos de funcionamento para implantar essas funções; operação que não é neutra em termos orçamentais. Legalmente, tal ação poderia levar a uma controvérsia na base da proteção constitucional conferida a minorias linguísticas em matéria de educação, sobretudo no que diz respeito à gestão das escolas. Além disso, nas últimas décadas, a dependência de caminho foi constituída pela predominância normativa do valor da "democracia escolar", apesar das críticas ao seu funcionamento. No caso de afirmarmos, como a maioria dos atores, que a democracia escolar se apresenta "doente", faz-se necessário constatar que muitos atores organizados estejam prontos a defendê-la e consideraram que os projetos de lei ligados à GAR poderiam melhorar esta democracia, com ferramentas de "transparência" que eles promoveriam (relato dos governantes e também relato sindical).

No período de implementação da GAR, os partidos políticos no poder reconhecem a importância da "democracia escolar" como um valor e uma herança democrática a se manter. No entanto, o recente questionamento da legitimidade democrática das CE feito pelo Partido Liberal, no poder desde julho de 2014, levou a relativizar a defesa das CE em nome da democracia. Os "governos locais eleitos" das CE (eleiçôes dos representantes e poder de tributação) não são considerados suficientemente democráticos, sob o pretexto de baixo índice de comparecimento às urnas nas eleições escolares (cerca de 5\%). Além disso, sua capacidade de gerir de maneira eficiente as verbas recolhidas pelos impostos escolares é denunciada, em um contexto de uma política de cortes no orçamento. Há, portanto, uma defesa ínfima das CE em nome da democracia escolar (e uma ameaça de transformá-las neste aspecto) e, principalmente a ideia de uma injunção ministerial nas CE para comprovar a eficiência no uso dos recursos.

Essa crítica às CE pelo governo atual pode fortalecer seu processo de conversão institucional (STREECK; THELEN, 2005) das CE, já iniciado com a implantação da GAR. As Comissóes Escolares (CE) devem assumir cada vez mais a função de gestor eficaz e eficiente dos recursos educacionais (apoio aos estabelecimentos), mas também de transmissor e vetor dos objetivos do ministério central. Sua função de expressão democrática de uma população local ou mesmo regional é na melhor das hipóteses questionável, pelo menos em suas formas atuais. Em última análise, este processo de conversão institucional poderia dar mais corpo à hipótese neoestatista promovendo o alinhamento das CE com o nível governamental.

\section{Um consenso circunstancial}

Finalmente, para entender essa trajetória neoestatista, podemos também sustentar um argumento centrado mais na análise do discurso dos atores 
envolvidos na construção das políticas educacionais de gestáo orientada por resultados. Houve no "Fórum da Comunidade da Produçáo de Políticas Educacionais" (FCPE) um tipo de aliança, se não foi explícita, pelo menos de consenso parcial, concomitantemente explícito e silencioso, entre os atores dos relatos dos governantes e dos sindicatos. Esse consenso foi construído especialmente "contra" o relato alternativo. Em outras palavras, além do impacto dos processos institucionais identificados acima, o caminho neoestatista tomado pela GAR no setor educacional no Quebec seria favorecido pelas convergências parciais de ideias e interesses. De fato, a análise das controvérsias entre os atores de diferentes relatos de ação pública, relacionada aos PL 124 e 88, destaca um certo número de convergências ${ }^{16}$ entre o relato sindical e o relato dos governantes: convergência parcial nos "problemas a resolver" (sucesso e democracia escolar), entre os meios e medidas de ação propostas (reforço do papel estratégico do Estado; necessidade de manter e supervisionar ainda mais as $\mathrm{CE}$ ). Essa convergência cognitiva é intensificada pelas convergências de interesse entre sindicatos e "governantes" (partidos do governo e CE): assim, a consolidaçáo das CE (e não a das escolas) pode ajudar, em primeiro lugar, as preocupaçóes sindicais em náo desmantelar as relaçóes sociais, particularmente no momento da negociaçáo do acordo coletivo (momento crucial nas relaçóes de trabalho no Quebec) e a evitar o excesso de dependência direta dos professores com relação à direção dos estabelecimentos. Por outro lado, essa evolução pode atender aos interesses da $\mathrm{CE}$ sem que os partidos do governo não a questionem, a partir do momento em que a prestação de contas por resultados da CE é prevista em lei.

Esta convergência parcial de interesses e visóes de políticas educacionais náo significa de modo algum que a GAR seja consenso no Quebec. Lembremo-nos que a história sindical duvida seriamente dos efeitos potenciais das ferramentas gerenciais da GAR (metas, prestação de contas dos resultados quantitativos) nas escolas, na medida em que, conforme argumentam, são uma ameaça à autonomia profissional dos professores os fins da educaçáo que os sindicatos defendem: um modelo de educação a serviço dos alunos, portador de igualdade de oportunidades e sucesso da maioria. $\mathrm{O}$ desacordo refere-se também à falta de ação do Governo contra o aumento desenfreado de uma lógica de competiçáo escolar das escolas, principalmente, entre o setor público e privado, fato que nos leva a questionar as finalidades do sistema público de educaçáo e a meta de oportunidades iguais.

\section{Conclusão}

O processo de mudança na forma de administração da educação no Quebec não é realizado pela importaçáo direta de modelos transnacionais, como a NGP, mas por uma recontextualização de suas ideias, condicionada tanto pela 
mediação de várias instituições, pela presença de mecanismos de mudança institucional gradual, como também pelas várias formas de transações políticas e simbólicas, cujo desenvolvimento é em nível do Quebec.

O fortalecimento do Estado e sua busca por eficiência são inscritos, inicialmente, na longa história das instituições quebequenses. É conivente com a valorização de uma "política verdadeiramente" educativa do Estado quebequense que esteja a serviço da "acessibilidade" e do "sucesso para todos", que se baseie em acordos institucionais existentes há muito tempo. A inércia parcial desses arranjos reflete tanto a ênfase do papel do Estado, como também as lógicas de sedimentação de dispositivos e ferramentas de regulação de geraçóes e de filosofias diversas que coexistem no sistema quebequense. Essa sedimentação de várias lógicas de accountability em tensão (RANSON, 2003) é acompanhada de processos de mudança institucional gradual, como a alteração dos instrumentos de democracia escolar local ou a conversão crescente das funçôes das CE, rumo a uma missão de "revezamento" de políticas governamentais de "gestão" ou "não-gestão" eficaz e eficiente dos orçamentos públicos. A trajetória neoestatista das reformas administrativas da educação no Quebec deriva das controvérsias cognitivas e das convergências e oposiçốes de interesses na recente construção dos PL 124 e 88.

A trajetória efetiva da Gestão orientada por resultados (GAR), portanto, tem contribuído para o fortalecimento do Estado na orientação e regulação do setor de educação pública; destinando uma perspectiva neogerencial orientada por resultados, reforçando ainda mais a Comissão Escolar no papel "intermediário" de mobilização dos atores locais a serviço das prioridades e objetivos mensuráveis dos governos. Assim, observa-se uma recontextualização da NGP em uma lógica mais neoestatista que neoliberal, juntamente com uma maior centralização e regulação burocrática clássica. Entretanto, ao mesmo tempo, esta política manteve alguns arranjos institucionais mais claramente orientados na preservação de prestação de contas local como parte de uma democracia escolar no nível da CE e das escolas. Ela também insistiu no setor privado e na possibilidade de escolha dos próprios pais.

Neste sentido, vemos como a lógica de accountability neogerencial da GAR associou-se a uma accountability burocrática e comunitária. Por outro lado, a preocupação sindical de manter a autonomia profissional e uma forma de accountability "profissional e comunitária" foi seriamente colocada em risco. O relato sindical pôde ajudar a conter a "relato alternativo" portador de uma accountability de mercado sem, entretanto, evitar a implantação das ferramentas de "gestão orientada por resultados", que ameaça, segundo eles, a autonomia profissional de seus mandatos e uma prestação de contas entre "profissionais" que busca preservar. As formas de accountability no Quebec são, portanto, fortemente heterogêneas e estão em constante tensão. 


\section{Notas}

1. Tradução de Elaine Andrade.

2. Na federação canadense, são as províncias (incluindo o Quebec) que têm o poder exclusivo de legislar em educaçáo. $\mathrm{O}$ ensino obrigatório (até 16 anos) é dividido em três níveis: pré-escolar, primário e secundário. O MELS define as diretrizes curriculares gerais e garante a alocação de recursos para a rede de ensino. As escolas reportam-se diretamente à entidade intermediária, isto é, as ditas comissóes escolares (CE), são $72 \mathrm{em}$ todo o país. Essas comissóes sáo divididas de acordo com a língua (Quebec é uma província francófona com uma minoria anglofalante). Finalmente, deve-se estar ciente de que há também um número significativo de escolas privadas que são, em sua maioria, subsidiadas pelo Estado. Essas escolas não fazem parte das CE.

3. Apoio da Fond de recherche Société et Culture Québec (FRQSC).

4. Trata-se de um construto cognitivo sobre o papel do Estado e de sua administraçáo, em grande parte inspirada por estas teorias de gestão no setor privado: a distinção entre governança (política) e gestáo, a autonomia relativa das organizações de prestadores de serviços, "orientação para o cliente", a definição de objetivos mensuráveis, ferramentas de avaliação e elaboração de relatórios de prestação de contas, importação de ferramentas do setor privado na gestão do setor público.

5. Sob forma de "histórias casuais", os detentores de um relato reúnem eventos, problemas, causas desses problemas, açóes, riscos em caso de não-ação; e por meio de relaçóes causais, eles promovem a implantação de soluçóes. Tornam os "[...] problemas sociais compreensíveis e acessíveis à açáo humana. Caracteristicamente, sugerem uma série de açóes em detrimento de outros [...]”. (RADAELLI, 2000, p. 257)

6. Segundo Eve Fouilleux (2000), os fóruns são lugares para debate "[...] mais ou menos especializados dentro do qual vários grupos de atores desenvolvem estratégias para validar sua visão de mundo.” Vários fóruns contribuem para a construção de políticas. A comissão "Educação" da Assembleia $\mathrm{Na}$ cional é para nós um fórum da comunidade de atores que, constantemente, ajuda a produzir e orientar as políticas educacionais, daí a noção de "fórum da comunidade da política educacional" (FCPE).

7. Foram analisadas para os projetos de lei 124 (2002) e 88 (2008): 1) 15 resumos apresentados pelos atores (nos planos institucionais, profissionais ou cívicos) à CCEANQ; 2) Uma amostra de debates (a partir de uma seleção de interlocutores visando representar as posições dos partidos políticos envolvidos) na CCEAN e na AN que precederam os votos dos projetos de lei.

8. Lei modificativa da Lei sobre a instrução pública e várias medidas legislativas, 1997, L.R.Q., c. $-\mathrm{I}-13.3$.

9. Lei sobre a modernização da administração pública, 2001, L.R.Q. c.-A-6.01

10. "A gestão orientada por resultados é uma abordagem de gestão com base em resultados mensuráveis atendendo aos objetivos e metas definidos com antecedência com base nos serviços a serem prestados. É vista num contexto de transparência, responsabilidade e flexibilidade quanto aos meios utilizados para alcançar os objetivos desejados". (SECRÉTARIAT DU CONSEIL DU TRÉSOR, 2002, p. 9)

11. Lei modificativa da Lei sobre o Conselho Superior de Educação e da Lei sobre instrução pública, 2002, L.R.Q., c.-I-13.3.

12. Lei modificativa da Lei sobre instrução pública e outros dispositivos, 2008, L.R.Q., c.-I-13.3.

13. Três tipos de atores organizados estão envolvidos: a Federação das CE (FCSQ), seus diretores (ADIGECS) e o pessoal (ACSQ).

14. A Federação dos sindicatos de ensino afiliada à Central Sindical do Quebec (CSQ) e a Federação autônoma de ensino (FAE) são os principais sindicatos que representam os professores da rede pública no Quebec. A Federação Nacional de Professores do Quebec (FNEEQ) associada à Confederação dos sindicatos nacionais (CSN) representa os professores secundários e universitários, uma grande parte do pessoal que apoia as escolas, bem como professores da rede privada.

15. Assim, formalmente, a lei 88 prevê que na ausência de melhora em consequência das metas náo 
cumpridas, o ministério pode impor medidas a uma CE. As CE também podem tomar medidas relacionadas às direçôes de estabelecimentos que não conseguem orientar suas equipes para atingir seus resultados.

16. Algumas dessas convergências foram explicadas em outras etapas. Por exemplo, sindicatos apoiaram explicitamente a retenção das $\mathrm{CE}$ alguns meses antes como parte do Fórum sobre Democracia e governança de conselhos escolares (2008).

\section{Referências}

BALL, S. J. What is policy? Texts, trajectories and toolboxes. In: (Org.). Education Reform. A critical and post-structural approach. Buckingham: Open Université Press, 1994, p. 14-21.

BARROSO, J. Autonomie et modes de régulation locale dans le système éducatif. Revue française de pédagogie, v. 130, p. 57-71, 2000.

BÉZES, P. Le renouveau du contrôle des bureaucraties. Informations sociales, v. 126, n. 6, p. 26-37, 2005.

BRASSARD, A. La question de la décentralisation en faveur de l'établissement dans le système d'éducation préscolaire et de l'enseignement primaire et secondaire (1979-2006). Québec: Fédération québécoise des directions d'établissement d'enseignement, 2007.

CAMPBELL, J. L. Institutional Change and Globalization. Princeton (NJ): Princeton University Press, 2004.

CLARK, D. Neoliberalism and public service reform: Canada in comparative perspective. Canadian Journal of Political Science/Revue canadienne de science politique, v. 35, n.4, p. 771-793, 2002.

CORBO, C. L'éducation pour tous: une anthologie du Rapport Parent. Montréal: Presses de l'Université de Montréal, 2002.

DEMBÉLÉ, M. et al. Perspective historique de la construction du modèle québécois de gestion scolaire axée sur les résultats. In: MAROY, C. (Dir.). L'école à l'épreuve de la performance. Les politiques de régulation par les résultats: trajectoires nationales, usages locaux. Bruxelles: DeBoeck, 2013, p. 89-106.

DENIGER, M.-A. Les politiques québécoises d'intervention en milieux scolaires défavorisés: regard historique et bilan critique. Revue française de pédagogie. Recherches en éducation, v. 178, p. 67-84, 2012.

FOUILLEUX, È. Entre production et institutionnalisation des idées. La réforme de la Politique agricole commune. Revue française de science politique, v. 50, n. 2, p. 277-306, 2000.

HOOD, C. A public management for all seasons? Public Administration, London, v. 69, p. 3-19, 1991.

. Contemporary public management: a new global paradigm? Public policy and administration, v. 10, n. 2, p. 104-117, 1995. 
KOGAN, M. Education Accountability. An analytic Overview. 2. ed. London: Hutchinson, 1988.

LESSARD, C. et al. Inventaire des politiques d'éducation au Québec portant sur l'enseignement primaire et secondaire de 1990 à 2006: analyse et impacts des politiques scolaires canadiennes sur le personnel scolaire (Projet 2). Montréal: Chaire de recherche du Canada sur les métiers de l'éducation Faculté des sciences de l'éducation Université de Montréal, 2007.

LESSARD, C.; MEIRIEU. L'obligation de résultats en éducation. Bruxelles: De Boeck, 2008.

MAROY, C.; DUPRIEZ, V. La régulation dans les systèmes scolaires. Proposition théorique et analyse du cadre structurel en Belgique francophone. Revue Française de Pédagogie, v. 130, p. 73-87, 2000.

MAROY, C. Vers une régulation post-bureaucratique des systèmes d'enseignement en Europe? Sociologie et Sociétés, XL, n.1, 31-55, 2008.

MAROY, C. et al. "La Gestion axée sur les résultats” au Québec: récits d'action publique, intérêts des acteurs et médiations institutionnelles dans la fabrication d'une politique éducative. Montréal: Chaire de recherche du Canada en politiques éducatives, Université de Montréal, 2013. Disponível em: < http://www.crcpe.umontreal.ca/documents/ RapportNew-AGE Axe1 FIN.pdf>

MULLER, P. L'analyse cognitive des politiques publiques: vers une sociologie politique de l'action publique. Revue française de science politique, v. 50, n. 2, p.189-207, 2000.

PONS, X.; VAN ZANTEN, A. Knowledge circulation, regulation and governance. In: DELVAUX, B.; MANGEZ, E. Literature review on knowledge and policy. 2007, p. 104-137.

POULX, J.-P. La genèse des États généraux sur l'éducation. In: GOSSELIN, G.; LESSARD, C. (Dir.). Les deux principales réformes de l'éducation du Québec moderne: témoignages de ceux et celles qui les ont initiées. Sainte-Foy: Presses de l'Université Laval, 2007.

RADAELLI, C. Logiques de pouvoir et récits dans les politiques publiques de l'Union européenne. Revue française de Sciences politiques, v. 50, n. 2, p. 255-276, 2000.

RANSON, S. Public accountability in the age of neo-liberal governance. Journal of Education Policy, v. 18, n. 9, p. 459-80, 2003.

ROCHER, G. Un bilan du Rapport Parent: vers la démocratisation. Bulletin d'Histoire politique, v. 12, n. 2, p. 117-128, 2004.

SCOTT, W. R. Institutions and Organizations. London: SAGE Publications, 1995.

STREECK, W.; THELEN, K. Beyond continuity: institutional change in advanced political economies. Oxford: Oxford University Press, 2005.

Recebido em 26 de julho de 2015.

Aprovado em 28 de setembro de 2015.

DOI: http://dx.doi.org/10.1590/ES0101-73302015152427 